Disclaimer: This article appeared in the AIMA Journal (June 2004), which is published by The Alternative Investment Management Association Limited (AIMA). No quotation or reproduction is permitted without the express written permission of The Alternative Investment Management Association Limited (AIMA) and the author. The content of this article does not necessarily reflect the opinions of the AIMA Membership and AIMA does not accept responsibility for any statements herein.

\title{
The Capacity Implications of the Search for Alpha
}

\section{By Hilary Till, Premia Risk Consultancy, Inc.}

Author's Note: This column is excerpted from an article that originally appeared in the Spring 2004 issue of the Journal of Alternative Investments.

Anjilvel et al [2001] emphasize the "alpha advantage" of hedge fund managers. They write, "Our research has shown that a significant proportion of the total return to hedge funds in the past has been alpha, in contrast with a small negative total alpha for mutual funds ..."

They hypothesize, "One possible explanation for an 'alpha advantage' ... is that ... [the active managers] can forecast expected returns better than others. This means a significant ability to exploit market inefficiencies to outperform their benchmarks, presumably by virtue of skill, knowledge, and insight."

This view of hedge fund management has a direct impact on the potential capacity of the hedge fund industry. To figure out the capacity of the hedge fund industry, we start by quoting from Cochrane [1999]: "... the average investor must hold the market so portfolio decisions must be driven by differences between an investor and the average investor."

If hedge funds are exploiting market inefficiencies, this means that other investors are supplying those inefficiencies. This means that, unfortunately, we can't all profit from exploiting inefficiencies. Therefore, there is a natural cap on the potential size of the hedge fund industry, assuming that hedge funds are indeed exploiting inefficiencies rather than taking in risk premiums.

Under this framework we can estimate how large the hedge fund industry could become based on the following three factors:

1. The maximum tolerance of the average investor for supplying inefficiencies;

2. The required return targets of hedge fund investors; and

3. The size of the global capital markets.

According to Anjilvel et al [2001], the size of the global equity and bond markets is $\$ 55$ trillion. Using this size of the global capital markets, Figure 1 shows the potential size of the hedge fund industry based on a give-and-take analysis between the suppliers and exploiters of market inefficiencies. 
Disclaimer: This article appeared in the AIMA Journal (June 2004), which is published by The Alternative Investment Management Association Limited (AIMA). No quotation or reproduction is permitted without the express written permission of The Alternative Investment Management Association Limited (AIMA) and the author. The content of this article does not necessarily reflect the opinions of the AIMA Membership and AIMA does not accept responsibility for any statements herein.

\section{Figure 1}

Capacity of Hedge Fund Industry (With an "Alpha Advantage") in Billions of Dollars

\begin{tabular}{rcccr|} 
& & \multicolumn{3}{c}{$\begin{array}{l}\text { Allowable Inefficiency in Private, Mutual } \\
\text { Fund and Institutional Fund Management }\end{array}$} \\
\cline { 3 - 5 } Required Excess & $10.0 \%$ & $-0.5 \%$ & $-0.75 \%$ & $-1.0 \%$ \\
\hline Return for & $7.5 \%$ & 2,750 & 4,125 & 5,500 \\
Hedge Funds & $5.0 \%$ & 3,667 & 5,500 & 7,333 \\
\cline { 3 - 5 } & & 5,500 & 8,250 & 11,000 \\
\hline
\end{tabular}

Source: Premia Risk Consultancy, Inc.

According to Putnam Lovell NBF and NewRiver [2002], the current size of the hedge fund industry is $\$ 500$ billion while the size of the global high net worth (HNW) and institutional marketplace is $\$ 44$ trillion. As of January 2004 , the size of the global hedge fund industry had grown to $\$ 700$ billion, according to Butcher [2004]. One might think that one could calculate how large institutional investment in hedge funds could become using Figure 1's figures. As an example, say the average investor can tolerate up to $-0.50 \%$ of inefficiencies in their traditional investments before competitive (or regulatory) forces would step in to keep this number from getting larger. Simultaneously, let's say hedge fund investors demand at least $10 \%$ in excess returns before committing their money to hedge funds. One might expect that hedge fund investors would require premium returns because these investment vehicles tend to be quite opaque and illiquid. Using these two assumptions, one could plausibly arrive at the size of the hedge fund industry becoming $\$ 2.75$ trillion (= $\$ 55$ trillion * $0.50 \% / 10 \%$.) This would mean that institutional and HNW investments in hedge funds could become $6 \%(=\$ 2.75$ trillion / \$44 trillion) of this sector's assets.

On the other end of the spectrum, if the average investor can tolerate $-1.0 \%$ in inefficiencies in how their money is invested, and if hedge fund investors only require $5 \%$ in excess returns before giving their money to hedge funds, one could envision the hedge fund industry being able to grow to $\$ 11$ trillion. The trouble with this conclusion is that one would expect competitive forces to step in at some point: there should be an interaction effect between the size and success of the hedge fund industry and the willingness of the average investor to tolerate mediocre investment management.

Therefore in viewing the predictions of Figure 1, one must caution that at some point the size and success of alpha-generating strategies can only attract so much capital before this would jeopardize their continuing success.

Analyzing the potential size of the hedge fund industry from a "demand point-of-view," Putnam Lovell NBF and NewRiver [2002] predict that by 2010, global HNW and institutional investment in hedge funds could become $3 \%$ of this sector's assets. See Figure 2. 


\section{Figure 2}

\section{Global Institutional and HNW Assets and Hedge Fund Adoption Curve}

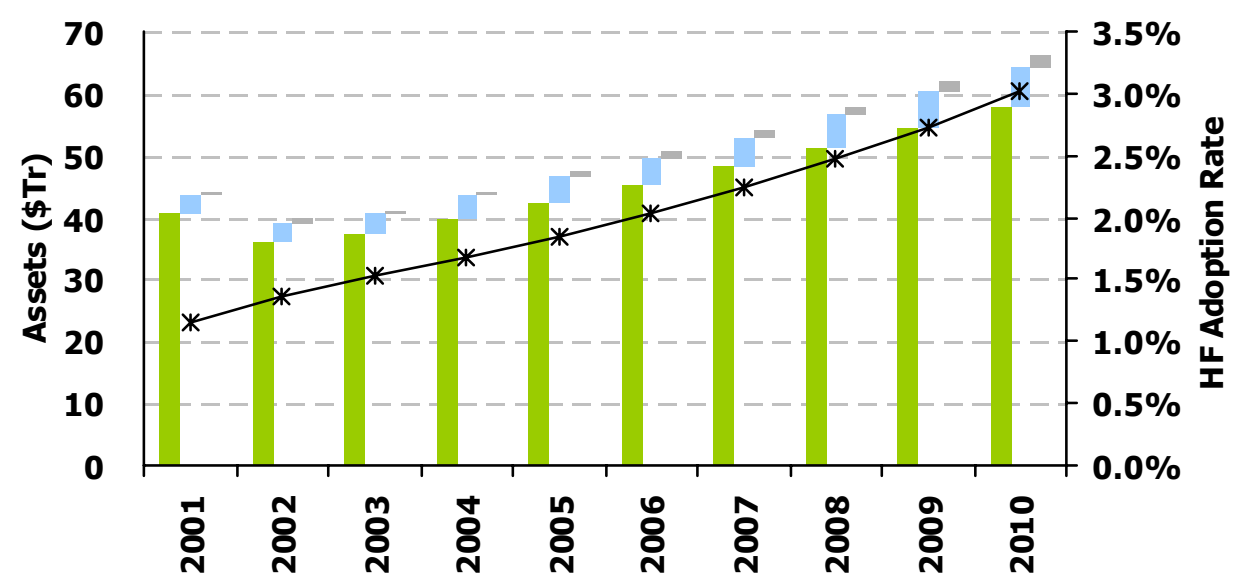

Authors' Data Sour Global traditional Greenwich Associales, iverviver esulliules.

Source: "Institutional or Institutionalized - Are Hedge Funds Crazy," Putnam Lovell NBF and NewRiver, White Paper, December 2002, Exhibit 2.

Using Figure 1's framework, it is plausible that such a size could be achieved from a "supply point-of-view." Using Putnam Lovell NBF and NewRiver's assumed growth in the size of the capital markets, their estimate would be consistent with the average investor tolerating $-0.25 \%$ in inefficiencies and the hedge fund investor requiring $10 \%$ excess returns on their investments.

There are a number of historical examples to point to in showing that superior investment strategies have historically been fleeting, which is why this article is sounding a cautionary note on predicting the potential size of the alpha-generating portion of the hedge fund industry. To provide a broad historical perspective, one can quote Siegel [2003]: "High-beta stocks beat low-beta stocks until William Sharpe discovered beta in 1964; small stocks beat large ones until Banz and Reinganum discovered the size effect in 1979 ...” 
Disclaimer: This article appeared in the AIMA Journal (June 2004), which is published by The Alternative Investment Management Association Limited (AIMA). No quotation or reproduction is permitted without the express written permission of The Alternative Investment Management Association Limited (AIMA) and the author. The content of this article does not necessarily reflect the opinions of the AIMA Membership and AIMA does not accept responsibility for any statements herein.

Gatev et al [1999] provide a more recent example. They simulate the performance of the equity pairs trading strategy. Over the period 1962 to 1997, they "... find average annualized excess returns of up to 12 percent for a number of self-financing portfolios of top pairs."

But they also find, "Pairs trading has declined in profitability dramatically from the 1970's and 1980 's to a low point at the end of our sample when the returns were sometimes negative." They hypothesize that after the strategy's discovery in the early 1980's, "competition has decreased opportunity."

Agarwal, Daniel, and Naik [2003] provide further evidence of the capacity-constrained nature of the hedge fund industry. Using data from January 1994 through December 2000, they note, "... large funds with large inflows display poor future performance and a lower probability of exhibiting persistence. This finding is consistent with decreasing returns to scale in the hedge fund industry."

\section{Selecting Alpha Generators Rather Than Beta Merchants}

Jensen and Rotenberg [2003] discuss examples of hedge fund style returns that could be replicated by passive investment techniques. Feldman [2002] summarizes this issue by asking, "Are hedge fund returns skill-based alpha-generators or efficiently-priced returns to bearing hidden risks?"

One would prefer to not "pay alpha fees for beta performance," as phrased by Siegel [2004]. Given this preference, have there been any studies so far on how to select hedge fund managers whose performance cannot be linked to known risk factors? The answer is yes. Chen and Passow [2003] and Mozes and Herzberg [2003] both provide evidence that such screens may be able to select superior managers in out-of-sample tests. What these studies cannot answer, though, is at what point would the popularity of such tests lead to the selected managers quickly reaching or exceeding their capacity constraints. 
Disclaimer: This article appeared in the AIMA Journal (June 2004), which is published by The Alternative Investment Management Association Limited (AIMA). No quotation or reproduction is permitted without the express written permission of The Alternative Investment Management Association Limited (AIMA) and the author. The content of this article does not necessarily reflect the opinions of the AIMA Membership and AIMA does not accept responsibility for any statements herein.

\section{Bibliography}

Agarwal, V., N. Daniel, and N. Naik. "Flows, Performance, and Managerial Incentives in the Hedge Fund Industry." Working Paper, Georgia State University and London Business School, 2002.

Anjilvel, S., B. Boudreau, B. Johmann, M. Peskin, and M. Urias. "Hedge Funds - Strategy and Portfolio Insights." Morgan Stanley Quantitative Strategies Research, 2001.

Butcher, J. "Onwards and Upwards." Hedge Funds Review (January 2004), pp. 11-12.

Chen, K., and A. Passow. "Quantitative Selection of Long-Short Hedge Funds." Working Paper, FAME and HEC Lausanne, 2003.

Cochrane, J. "Portfolio Advice for a Multifactor World." Economic Perspectives, Federal Reserve Board of Chicago (Third Quarter 1999), pp. 59-78.

Feldman, B. "Portfolio Construction with Alternative Investments." Ibbotson Associates Research, Presentation to Chicago QWAFAFEW, 8/22/02, http://www.qwafafew.org/chicago/handouts/feldman2august2002.pdf.

Gatev, E., W. Goetzmann, and K. G. Rouwenhorst. "Pairs Trading: Performance of a Relative Value Arbitrage Rule.” Working Paper, Yale School of Management, 1999.

Jensen, G. and J. Rotenberg. "Hedge Funds Selling Beta as Alpha." Bridgewater Daily Observations, 6/17/03.

Mozes, H., and M. Herzberg. "The Persistence of Hedge Fund Risk: Evidence and Implications for Investors." Journal of Alternative Investments (Fall 2003), pp. 22-42.

Putnam Lovell NBF and New River Research. "Institutional or Institutionalized - Are Hedge Funds Crazy." December 2002.

Siegel, L., Benchmarks and Investment Management. Charlottesville, VA: Association for Investment Management and Research, 2003.

Siegel, L., "Managing Active Return and Risk for Alternative and Traditional Investments." The Ford Foundation, Presentation at Ibbotson Client Conference, Orlando, 1/20/04. 